\title{
Urdimento
}

\section{CINE HORTO GALPÃO: UM PROJETO ARTÍSTICO PEDAGÓGICO}

\author{
Éder Sumariva Rodrigues ${ }^{1}$
}

\section{Resumo}

Este texto aborda a trajetória do Grupo Galpão a partir do reconhecimento das diversas linguagens que sustentaram as montagens realizadas pelo grupo. Este reconhecimento permite perceber que o projeto pedagógico do grupo conforma um sistema aberto, destinado a constante formação do ator e a busca incansável de novos procedimentos, novas imersões cênicas. O grupo realiza ações pedagógicas através de um projeto catalisador das experiências produzidas ao longo de sua trajetória do grupo. O texto ainda identifica o projeto Galpão Cine Horto como um centro de referência para criação, pesquisa e fomento teatral.

Palavras-chave: Grupo Galpão, projeto pedagógico, Galpão Cine Horto.

\begin{abstract}
This text approaches the pathway of the Galpão Group theatre where of the recognition of the different languages to support the realized montage of the group. This recognition allows realizing pedagogic project of the group as an open system, destined to the constant formation of the actor and the tireless pursuit of the news procedures, news cenics immersions. The group realizes pedagogic actions through of the catalyst project of the produced experience along of the its pathway of the group. The text still identifies the project Galpão Cine Horto as a centre of reference to creation, research and theatre furtherance.
\end{abstract}

Keywords: Galpão Group, Pedagogic Projetc, Galpão Cine Horto.

\section{Grupo Galpão: a trajetória dos espetáculos}

O Grupo Galpão foi criado por cinco atores em 1982, após uma experiência de trabalho com o diretor George Frosher e o ator Kurt Bildstein, ambos do Teatro Livre de Munique. O Grupo Galpão ao longo de sua trajetória concentrou seus esforços em pesquisa de linguagem, percorrendo as mais diversas técnicas, buscando a introdução de novos referentes técnicos para o grupo. Neste sentido diversificou o olhar da direção, alternando convite a diferentes diretores, e eventualmente trabalhando com a direção de um dos integrantes do grupo.

Éder Sumariva Rogrigues é Mestrando do Programa de PósGraduação em Teatro na Universidade do Estado de Santa Catarina (UDESC).

Participa do projeto de pesquisa "0 Teatro de Grupo e a Construção de modelos de trabalho do ator". E-mail: sumariva rodrigues@yahoo. com.br 


\section{Urdimento}

Nas diferentes encenações do grupo funcionaram sempre como estímulo à prática de pesquisa atorial. Por isso, o Galpão busca incorporar ao processo de ensaios a aprendizagem de técnicas que satisfaçam a necessidade para a montagem que estão realizando, mas que ao mesmo tempo impulsionem o grupo de atores a novos territórios. O desenvolvimento desse processo associado de aprendizagem e ensaio criativo pode ser considerado uma das matrizes geradas pelo grupo desde de seus primeiros passos. Consequentemente podese dizer que o trabalho grupal aparece imerso sempre na descoberta das novas possibilidades cênicas que vão além do desenvolvimento dos espetáculos.

A primeira opção do Grupo Galpão foi encenar na rua, em 1982, " $E$ A Noiva Não Quer Casar" com direção coletiva e texto de Eduardo Moreira, utilizando elementos da linguagem circense. Logo em seguida, em 1983, levaram à cena o espetáculo infantil "De Olhos Fechados" sob direção de Fernando Linares e autoria de João Vianney e, em 1984 encenam o espetáculo de teatro de rua "Ó Procê Vê na Ponta do Pê" (criação coletiva), espetáculos nos quais o grupo ensaiou a utilização da linguagem clownesca. Sob direção de Eduardo Moreira e Fernando Linares, encenam em 1985 o texto de Carlo Goldoni "Arlequim Servidor de Tantos Amores", experimentam técnicas da Commedia dell'Arte e da máscara italiana que, posteriormente em 1986 foi aprofundado na montagem de criação coletiva e direção de Paulinho Polika "A Comédia da Esposa Muda - que Falava Mais do que Pobre na Chuva". No mesmo ano, "Triunfo, um Delírio Barroco", Carmen Paternostro foi responsável pela direção, concepção cênica e roteiro final do espetáculo, representou uma experiência com a Cia. de Dança do Palácio das Artes.

Seguindo o viés experimental, em 1987 o grupo encenou o texto de Eduardo Moreira e Antonio Edson - que também foi responsável pela direção "Foi Por Amor", esquete que abordava a realidade brasileira criticando os crimes passionais e o machismo dominante na sociedade. "Corra Enquanto é Tempo" foi encenado em 1988 com autoria e direção de Eid Ribeiro, uma paródia sobre grupos religiosos evangélicos que utilizava espaços da rua muito similares aos abordados pelos grupos religiosos. Também sob direção de Eid Ribeiro, "Álbum de Família" (1990) texto do dramaturgo Nelson Rodrigues marcou o retorno ao palco, e significou oportunidade para experimentação atorial com uma dramaturgia mais trágica e densa. Esta encenação foi marco divisor na estrutura organizacional do grupo, conseguiram adquirir a própria sede, o Galpão.

"Romeu e Julieta" (1992) espetáculo de teatro de rua inspirado na obra de Willian Shakespeare e com direção de Gabriel Villeta, teve uma repercussão que contribuiu de forma significativa para o reconhecimento nacional do grupo, retratava o universo cultural do sertão mineiro, e ajudou a conformar uma imagem do grupo, constituindo quase uma marca do Galpão.

Cine Horto Galpão: um projeto artístico pedagógico. Éder Sumariva Rodrigues. Dezembro 2008 - № 11 


\section{Urdimento}

O encontro com Villeta significou uma reestruturação no interior do grupo, gerou uma estrutura profissional que deu suporte aos posteriores trabalhos desenvolvidos pelo Galpão. Com a projeção conquistada pelo trabalho de direção de Villela, tanto a nível nacional e internacional ${ }^{2}$, o grupo decidiu continuar com novas concepções teatrais trazidas pelo diretor paulista.

Seguindo o processo de renovação teatral, Villeta decide montar a partir da adaptação de Arildo de Barros do texto de Eduardo Garrido "O Mártir do Calvário" o espetáculo "A Rua Amargura” (1994). Esta encenação representou uma continuidade neste processo de formalização dessa imagem do grupo, ao associar a temática bíblica com elementos característicos da cultura popular brasileira.

"Um Molière Imaginário" (1997) foi adaptado a partir do texto "Um Doente Imaginário", último texto escrito por Jean-Baptiste Poquelin, mais conhecido como Molière. Este espetáculo foi dirigido por Eduardo Moreira e constituiu um momento de consolidação grupal e autonomia interna, "o grupo procurava andar com suas próprias pernas” (BRANDÃO, 2002: 138). Por um lado havia a pressão da continuidade qualitativa dos trabalhos realizados anteriormente que consequentemente refletia na expectativa do público.

Em 1998, o ator e diretor Cacá Carvalho ministra workshop com o Grupo Galpão baseado no tex to O Cavaleiro Inexistente de Ítalo Calvino. A partir dessa experiência, o ano seguinte foi marcado pela produção do espetáculo "Partido" (1999) adaptado da obra “O Visconde Partido ao Meio”, também do escritor italiano Calvino. Carvalho nesta encenação explorou uma linguagem mais poética experimentando o universo existencialista. Esta produção marcou os 17 anos de trajetória e consolidação do trabalho desenvolvido pelo grupo. "Um Trem Chamado Desejo" (2000) do autor americano Tennessee Williams e dirigida por Chico Pelúcio, outro fundador do grupo. Este espetáculo foi concebido como comédia musical, recriava o difícil dia-a-dia de uma companhia teatral dos primeiros anos do século XX, estabelecendo um inevitável paralelo com a própria vida do grupo.

"O Inspertor Geral" (2003) do russo Nicolai Gógol sob a direção de Paulo José representa uma reafirmação da estratégia do Galpão de se associar a diretores já renomados para experimentar novos caminhos. Essa parceria se reafirmou com a estréia em 2006 de "Um Homem é um Homem" do dramaturgo alemão Bertolt Brecht é possível visualizar outra vez o projeto cênico de Paulo José buscando uma articulação com o capital técnico do elenco grupal.

Esta trajetória, que consolidou um espaço significativo no contexto teatral brasileiro, se articulou a partir de um projeto grupal que insistiu na formação técnica dos atores. Isso possibilitou a experimentação de diversas linguagens cênicas propostas pelos diretores convidados. Os atores do Galpão

\author{
${ }^{2} \mathrm{O}$ Galpão foi convi- \\ dado para apresentar \\ o espetáculo "Romeu \\ e Julieta" no Globe \\ Theatre (Londres/ \\ Inglaterra). Globe \\ Theatre é uma fiel \\ reconstrução do \\ teatro construído em \\ 1599 , onde trabalhou \\ Shakespeare e para \\ qual escreveu muitas \\ peças de teatro. É \\ um único teatro in- \\ ternacional dedicado \\ à exploração da obra \\ de Shakespeare.
}




\section{Urdimento}

${ }^{3}$ Artigo para 0 programa "Grupo Galpão: Uma História de Risco e Rito".
${ }^{4} 0$ site do Galpão Cine Horto pode ser acessado pelo endereço: www. galpaocinehorto. com.br

${ }^{5} 0$ site da Redemoinho pode ser acessado pelo endereço: www. redemoinho.org conformaram um capital criativo muito favorável para a apropriação de uma multiplicidade das possibilidades cênicas. Assim, o grupo pode pautar-se "por um teatro de pesquisa, onde o riso e a possibilidade são a tônica. Impulsionados pelo desejo de fazer um teatro calcado no desenvolvimento de uma própria linguagem de grupo"3 (MELLO, 2001: 01).

Este coletivo de atores articulou sua prática cênica com um projeto coletivo de construção de uma estrutura de trabalho que permitisse o aprofundamento técnico e a sobrevivência por meio do teatro. Por isso a referência da aprendizagem caracteriza o grupo.

\section{Galpão Cine Horto: espaço de pesquisa, aprendizagem e fomento do teatro}

Desde seus primeiros anos de trabalho o Galpão almejava ir além da criação de espetáculos. Em 1984, com apenas dois anos de existência e, contando com a jovialidade de seus integrantes as perspectivas promissoras do grupo eram visíveis também para a crítica. O jornalista Marcelo Procópio do Jornal Estado de Minas registrou em 14/10/1984 os anseios e os desejos desse conjunto de atores que mais tarde tornar-se-ia realidade:

Eles acreditam que é possivel ser profissional de teatro aqui [em Belo Horizonte]. Trabalham cerca de cinco horas por dia, buscam ter uma infra-estrutura que garanta a vida do grupo. E insistem no grande sonho do espaço: um galpão para espetáculo, escola. (apud BRANDÃO, 2002: 75)

Essa dinâmica de trabalho profissional, baseada na disciplina e no companheirismo, repercutiu no projeto que redundou na abertura de um espaço cultural que representou um passo decisivo para o desenvolvimento artístico do Grupo Galpão.

A percepção de que este "novo espaço simboliza o esforço destes quinze anos e inaugura os próximos que virão" (BRANDÃO, 2002: 146), impulsionou o grupo a assumir um projeto que demandou um grande esforço de produção.

A abertura do espaço Galpão Cine Horto ${ }^{4}$, significou um importante acontecimento para a vida cultural de Belo Horizonte, proporcionou o desenvolvimento e fomento da criação teatral, compartilhamento de idéias e pesquisa bem como posteriormente repercutiu no nascente movimento de coletivos teatrais denominado Redemoinho ${ }^{5}$.

Vizinho da sede do grupo na Rua Pitangui, o Cine Horto era um antigo cinema abandonado, que foi transformado a partir da intervenção do 


\section{Urdimento}

grupo no momento de expansão de suas atividades. Isso se deu também a partir de discussões com artistas da cidade.

O Cine Horto Galpão, inaugurado em março de $1998^{5}$, tornou-se um centro cultural que cumpre múltiplas funções, tendo como o eixo norteador à reciclagem de atores. Assim, o Cine Horto possibilita aos artistas locais o aprofundamento de técnicas, a realização de pesquisas, e formação técnica, além de ser um centro de fomento do teatral.

Nos seus onze anos de trajetória, o Cine Horto abrigou projetos concebidos pelo grupo, que visavam suprir carências identificadas pelo Grupo no ambiente teatral de Belo Horizonte. O Cine Horto tornouse lugar de encontro de pessoas do teatro mineiro, possibilitando trocas de experiências entre diferentes grupos, bem como também contato com artistas de outras regiões do país.

O espaço também funciona como sitio de veiculação de projetos culturais produzidos na cidade. Neste sentido, seu principal eixo é a geração e a difusão de produtos teatrais. Estas tarefas são realizadas a partir de uma política de abertura para a comunidade civil e artística, criando oportunidades para o acesso às atividades desenvolvidas tanto neste centro cultural.

Com a intensa carga de viagens que o Galpão realiza durante todo o ano, alguns projetos são realizados por profissionais, que se destacam no circuito teatral de Belo Horizonte, e são contratos pela direção do Cine Horto. Assim, o Cine Horto opera como um projeto de extensão do grupo, criando oportunidades de ensino e aprendizagem teatral através de diferentes atividades. Com apresentações de espetáculos, conferências, oficinas e encontros, o grupo estabeleceu um projeto que fomenta o acesso ao teatro e, dessa forma, discute os modos de criação e produção ao mesmo tempo em que constitui um lugar de encontro.

Os projetos, atualmente em curso no Cine Horto, em suas especificidades atendem a diferentes anseios dos artistas. O projeto Oficinão ${ }^{6}$ está dirigido à realização de uma pesquisa temática que relaciona membros do grupo Galpão com alunos participantes. Neste projeto, o grupo aplica junto aos alunos, técnicas desenvolvidas no trabalho cotidiano do grupo, e particularmente aquelas absorvidas a partir da experiência com os diferentes diretores convidados.

No Oficinão também se busca a elaboração de novos exercícios, e o aprimoramento de técnicas. Este projeto permite que os alunos participem de uma encenação que supõe o envolvimento com a construção geral do espetáculo desde a produção, realização de figurinos e cenários, além da
${ }^{5} 0$ Grupo Galpão já tinha 16 anos de trajetória quando inaugurou o Cine Horto, portanto os atores tinham diversas experiências de linguagens.
${ }^{6} \mathrm{~A}$ primeira edição aconteceu em 1998 com a direção de Chico Pelúcio com o espetáculo

"Noite de Reis". Até a oitava edição, totalizou-se 30.000 espectadores com 285 apresentações neste espaço cultural. 


\section{Urdimento}

${ }^{7} 0$ primeiro festival aconteceu em 2000. interpretação. Assim, esta oficina termina por conformar uma instância de formação de novos grupos, dado que, ao finalizar o projeto, vários alunos se reúnem para dar seguimento aos seus processos criativos.

O Festival de Cenas Curtas $3 X 4^{7}$ é um projeto de estímulo à criação cênica e a revelação de novos talentos. A seleção dos espetáculos breves é feita pelo Grupo Galpão e convidados e tem como critério de avaliação a pesquisa e da proposta teatral dos grupos proponentes. O Festival propõe que os grupos elaborem uma apresentação de um esquete, em aproximadamente 15 minutos. As esquetes são submetidas ao voto popular, e o ganhador ganha como prêmio a possibilidade de realizar uma temporada no Galpão Cine Horto.

Sabadão é um evento mensal que tem por finalidade realizar aulasespetáculo, palestras, debates ou exibição de vídeo, sempre com a presença de um artista renomado das artes cênicas, que interagem com o público. A troca de experiências proporcionada por este projeto permite o contato direto com a comunidade artística local que, a partir disso, tem a oportunidade de interagir com outras formas de reflexão sobre a cena teatral brasileira.

Aproveitando a própria história do Cine Horto, o Grupo Galpão insere no projeto Conexão Galpão dois tipos de atividades que têm a prioridade de atender estudantes e comunidade em geral, realizando assim um programa educativo na cidade. Já o Conexão Cinema, difunde a história do cinema, relacionando-a, quando possível com a própria história do local. Para isso o grupo utiliza a pequena sala de projeção que foi conservada no Cine Horto. Este projeto atende crianças de 5 a 10 anos relacionadas com diferentes instituições. Conexão Teatro é um projeto que se dedica à história do teatro e suas transformações, e está destinado às crianças e aos pré-adolescentes, abarcando a faixa etária dos 9 aos 12 anos.

Retomando as origens do grupo, o projeto Cine Horto Pé na Rua, proporciona a vivência do teatro de rua. Assim, os alunos que freqüentam este projeto podem experimentar a linguagem da rua que foi a matriz do trabalho do Galpão. Ao abordar o uso da rua o projeto amplia as perspectivas de intervenção cênica dos atores nos espaços da cidade, propondo a criação de novas formas de imersão artística. A primeira montagem deste projeto intitulou-se "Papo de Anjo" com a direção de Chico Pelúcio e Lydia Del Picchia, e foi realizada com os atores participantes do projeto Oficinão de 2003/2004.

Ultrapassando as fronteiras da cidade de Belo Horizonte, o Grupo Galpão lançou, em 2004, o projeto Redemoinho - Rede Brasileira de Espaços de Criação, Compartilhamento e Pesquisa Teatral tem como finalidade reunir grupos de teatros que administram o próprio espaço de criação, o compartilhamento e a troca de experiências entre os grupos. As agrupações que compõem a rede de integração Redemoinho possuem espaço próprio para criação e pesquisa 


\section{Urdimento}

cênica. Esta rede de integração discute a produção teatral do Brasil, troca experiências e busca, através deste intercâmbio, fortalecer as bases de fomento cultural no país. O projeto Redemoinho caracteriza-se pela descentralização ${ }^{8}$, visando realizar o evento em todos os espaços culturais dos grupos integrantes, realizando o evento a cada ano em uma sede diferente.

\section{Palavras finais}

O projeto do Galpão, grupo que nasceu de uma oficina em um evento teatral, consolidou a criação de um espaço de fomento que funciona como berço de novos grupos. Por isso, pode-se dizer que as atividades desenvolvidas no Cine Horto Galpão conformam um projeto pedagógico de impacto tanto local como nacional. Este projeto, além de oferecer aprendizagem técnica, também repercute como modelo de prática pedagógica grupal, apesar de que as condições de trabalho do Cine Horto Galpão sejam de difícil reprodução ao longo do país. Atualmente, o Cine Horto além de desenvolver projetos focados no fomento e produção teatral, possui outros dois projetos em andamento que completam a estrutura de funcionamento idealizada pelo grupo: o Centro de Memória e Pesquisa do Teatro que abriga acervo bibliográfico e videográfico especializado na área teatral e, desde 2004 publica anualmente a Revista de Teatro Subtexto, objetiva colocar em circulação as experiências dos coletivos de teatro.

A política de compartilhamento levada a cabo no Cine Horto implica na abertura do grupo a novos olhares, por isso este espaço se constituiu em lugar de criação e de reflexão, onde se reflete sobre o fazer teatral em grupo.

\section{Referências bibliográficas}

BRANDÃO, Carlos Antônio Leite. Grupo Galpão: Uma história de risco e rito. $2^{\circ}$ ed. Belo Horizonte: o grupo, 2002.

MELLO, Sérgio Bandeira de. Grupo Galpão: Uma História de Risco e Rito. 2001.

MOREIRA, Eduardo da Luz. Grupo Galpão: Diário de Montagem A Rua da Amargura. Belo Horizonte, UFMG, 2003.

PELÚCIO, Chico. Galpão Cine Horto - Espaço de criação e incentivo ao trabalho em grupo. Revista Subtexto, Belo Horizonte, v. 01, n 01, rona 2004.

RODRIGUES, Eder Sumariva. Características e perspectivas da identidade do Teatro de Grupo no Brasil. In III JORNADA PEDAGÓGICA NACIONAL DO SINPRO, 2005, Santa Catarina: Itajaí, 2005. p. 67-77.
${ }^{8} 2004$ e 2005 na sede do Grupo Galpão em Belo Horizonte; 2006 na sede Barracão Teatro em São Paulo; e em 2007 será realizado em Porto Alegre na sede do Grupo de Atuadores Terreira da Tribo Ói Nóis Aqui Traveiz. 